\title{
Customer Role in the integration of EVs with the Colombian electricity market
}

\author{
L. M. Hinestroza Olascuaga \\ Department of Electrical Engineering \\ Universidad de la Costa \\ Barranquilla, Colombia
}

\author{
J. A. Rosero García \\ Department of Electrical and Electronics \\ Engineering \\ Universidad Nacional de Colombia \\ Bogotá D.C, Colombia
}

\author{
Omar F. Prias Caicedo \\ Department of Electrical and Electronics \\ Engineering \\ Universidad Nacional de Colombia \\ Bogotá D.C, Colombia
}

\begin{abstract}
Mass adoption EVs in Colombia, is presented as a necessary option not only to mitigate the impact of the transportation sector on the environment but to promote a more efficient vehicle fleet. The impact of EVs on the Colombian electricity sector is associated with the uncontrolled charging process of EVs, which ultimately results in high peaks in the demand curve. Therefore, the level of flexibility of user habits will be the key in the interaction of EVs with the grid. User can recharge the vehicle whenever he requires and only he will have control on it, if there is a regulatory scheme that defines it or a series of incentives that promotes the controlled charging. Currently, there is not any regulation which determines if the scheme of the electricity tariff will apply to EVs. This paper analyzes the requirements, user habits, the operation scheme of the Colombian electricity market and the possible solutions required to promote the adoption of EVs and to reduce the impacts of EVs on the electricity market and on the user economy.
\end{abstract}

Index terms - customer perception, electric vehicles, electricity market, mass adoption, mobility

\section{INTRODUCTION}

Due to climate change and reduction of oil reserves, the introduction of EVs to market represents a clean and sustainable solution for the transportation sector in cities. The use of means of transportation is present in almost every aspect of our daily activities and so that, it is necessary to implement changes in order to reduce emissions of greenhouse gases and noise pollution, to increase the energy efficiency in the vehicle fleet, to promote sustainable cities and to improve people quality life.

In the case of Colombia, the transportation sector consumes $38.3 \%$ of the total energy produced in the country and mainly it uses two types of energy sources derived from oil, like Diesel $42.8 \%$ and Gasoline $35.7 \%$ [1 ] . This type of consumption is a concern about the depletion of oil reserves, in addition to the responsibility of contributing massively to global warming.

The entrance of EVs to Bogotá D.C., brings challenges at all levels: standardization, regulation, incentives and government policy, change in the mobility of the city, integration with the power grid and adoption by the user.

The massive adoption of EVs technology will depend on the willingness of customers to adapt their established habits (driving patterns), acquired with conventional vehicles, to EVs. According to [2], many studies has focused on analyze the impacts of EVs from the point of view of the electricity grid, but not evaluating the customer role, who decides to adopt or not the technology.

Therefore, this paper presents a methodology that evaluates the customer perception of EVs. It identifies driving patterns, driving routines, willingness to change their conventional vehicle and requirements and constraints to adopt an EV. It is described how the scheme of the electricity tariff must change in order to promote the use of EVs in the cities, without affecting the user economy.

The obtained results not only allow defining if the Customer in Bogotá will adapt his patterns to EVs technologies, with their limitations, but determining the strategies to promote the use of EVs, through incentives or public politics that benefits the customer and the electricity market.

\section{BACKGROUND}

In the past three (3) years, evaluation methodologies (surveys) have been proposed both in the United States and in Europe [3-6], focused on: 1) assessing the user's adaptation to EVs in terms of driving patterns, mobility, comfort, charging routines, change in the consumption of energy and interaction with the charging infrastructure and 2) evaluating the perception of the user respect to the massive entry of EVs for the first time.

In Colombia, there is no a previous reference from where the perspective of the user about EVs entry can be inferred. Thereby, this study is the first one aimed to achieve it. However, there is a reference for the most important mobility indicators; in Bogotá, $92 \%$ of registered vehicles are private or for particular use [6] and their main source of energy is ACPM / Diesel. In 2011, it was estimated that the average speed of drivers in Bogotá D.C. was $23,27 \mathrm{~km} / \mathrm{h}$, the average time spent per day to move corresponded to 64,8 minutes, the maximum distance traveled per day was $30 \mathrm{~km}$ and $72 \%$ of drivers responded that the main reason for driving in the city was going to work.

\section{METHODOLOGY}

The user is who guarantees the mass adoption of EVs and its position on the market. This study focuses mainly on analyzing the customer perception of EVs in the city of Bogotá. Specifically, based on the results, there will be identified in which aspect it is necessary to define incentives to mitigate the impact of EVs on the electricity market. 
An evaluation methodology has been developed through a survey in order to know the opinion of the customers and especially to identify the most relevant aspects between technical requirements and constraints when purchasing an EV.

The methodology implemented is described as follows:

\section{A. Sample Design}

\section{Target Population}

Adults (age $>18$ years old) who turns to a car dealer because there is an immediate or short-term interest to buy a car

Target space

The list of commercial car dealers registered in the Bogotá Commerce Chamber (CCB)

\section{Statistics Method}

The methodology is based on the inferential statistics. It applies the random sampling method by clusters. In this sampling rate the sample unit is a group of elements of the population that forms a unit, which is called cluster [7]. The sample consists of randomly selecting a certain number of clusters (the required to achieve sample size) and then investigate all elements within the chosen clusters. This method has the advantage of simplifying the analysis of sample data.

In this case, this sampling method was used because there is not any reference or sampling frame of the potential customers of EVs and so that, it was necessary to identify the list of car dealers in the city, due the fact that most people move to them if they want to purchase.

By defining the sampling frame, the dealers would be the clusters. The census was implemented in the following time zones (from 10:00 to 13:00 and 17:00-19:00) because is the peak period in which more people attend the commercial locals. So that, people was surveyed on that schedule.

It was found that there are 390 legal registered car dealers. Applying a random sampling method, from the total commercial locals it was taken only 39 corresponding to $10 \%$ of the total. This technique also randomly selects the elements, in this case, people to be surveyed. The procedure is as follows: 1) A number is assigned to each person of the population and 2) through some mechanical means (balls in a bag, tables of random numbers, random numbers with a calculator or computer) many subjects are chosen until to complete the required sample size.

Additional to this method, car dealers were selected using the method of negative coordinated, which generates $N$ random numbers, assigns them to each of the elements, sort elements according to the random values as and considers as sample the elements corresponding to the $n$ random smaller values.

Equation (1) is applied to obtain the sample size $n$. This corresponds to the formula of the sample size defined by the simple random sampling method [7], because the total of the population is known:

$$
n=\frac{N}{1+\frac{e^{2}(N-I)}{Z^{2} p q}}
$$

Where:

$n$ : sample size

$N:$ is the number of car dealers, it means 390

$e$ : sampling error

$p q$ : variance between car dealers

$Z_{\text {value }}$ : level of confidence, for a $95 \%$ confidence interval, the $\mathrm{z}$-value is 1.96

In order to obtain the variance between car dealers, it is necessary to obtain the results from an initial sample or pilot test of the survey. Therefore, a form of questions is designed and applying the described statistics methods, 195 customers (135 males and 60 females) were surveyed in the selected 39 car dealers.

Having the results, the question number 21, was selected in order to calculate the variance. This question refers to: How much should gasoline rise in order you seriously consider to buy an EV? It had four possible answers: a) Less than US\$ 4.6 ; b) US\$ 4.65 to US\$ 5.3 ; c) US\$ 5.35 to US\$ 6.75 ; d) US\$ 6.8 to US\$ 7.8; e) More than US\$ 7.8 and f). I would never buy an EV.

With this question the variance between car dealers was 0.07452991 and the sample size with a level of confidence of $95 \%$, for different errors (with a maximum error of $15 \%$ ) was calculated using (1). Table I presents the obtained results:

TABLE I. SAMPLE SIZE FOR DIFFERENT ERRORS

\begin{tabular}{|c|c|}
\hline Error & $\boldsymbol{n}$ \\
\hline 0.05 & 88.39 \\
\hline 0.06 & 66.03 \\
\hline 0.07 & 50.83 \\
\hline 0.08 & 40.16 \\
\hline 0.09 & 32.45 \\
\hline 0.10 & 26.71 \\
\hline 0.15 & 12.35 \\
\hline
\end{tabular}

Considering the research budget, it was selected an error rate of five percent $(5 \%)$, which implies a sample size of eightyeight (88) car dealers in which the final survey must be applied.

This paper describes the results of the pilot test, which allowed defining the questions form and then corrects it with the suggestions of the respondents. Also, pilot test allows calculating the sample size of the final survey.

In future studies, the obtained results from the final survey will be analyzed using a descriptive multivariate analysis. Through this, a series of inferences from the population represented by the sample will be done.

\section{Target methodology implementation time}

The information was collected for one (1) month of fieldwork and the 195 respondents were personally surveyed, through twenty-eight (28) questions including: closed, multiple choice and scaled score of 1-5 (Likert scale) answers.

\section{B. Survey form definition}

The questions were defined focusing them on aspects such as driving patterns, mobility indicators, willingness to buy an $\mathrm{EV}$, interest to acquire an $\mathrm{EV}$ and main expectations about EVs. The survey was grouped into four (4) parts according to the thematic to be addressed: 


\section{Characterization of the user}

Questions focused on determining the profile or characteristics of possible potential customers of EVs in terms of gender, age, average monthly income, level of education, among others.

Knowledge about EVS

Questions focused on assessing what kind of knowledge the user has about EVs and its associated concepts. Specifically, if the person knows about the different types of EV technologies, modes and charging times, ranges, maximum speeds, prices, among others.

User Requirements and constraints to purchase an EV

Questions focused on identifying the main issues (positive and negative) that customers would consider when purchasing an $\mathrm{EV}$ and what the minimum requirements to be met by the EVs are in order to purchase one.

User interest in purchasing an EV

Questions focused on knowing how willing people are to buy an EV, when they will buy one (short-long terms), which over cost the person would pay, in which sector the user considers that it is more important to implement this technology and what type of vehicle they would buy.

\section{RESULTS}

Taking as a reference the purpose of this paper, the results associated with the main requirements that customers have respect to an $\mathrm{EV}$, the barriers that customers have to buy an $\mathrm{EV}$ and driving patterns and driving habits are showed.

The analysis of these results will determine how to influence on driving patterns of people and what kind of incentive should be defined to mitigate the impact of EVs on the electricity market, specifically on the demand curve of the city (Bogotá D.C.)

\section{A. Characterization of the user}

The following results focus on identifying the predominant characteristics of the potential EV user. It is concluded that:

- $72 \%$ of participants were men

- $66 \%$ are between 18 and 37 years old

- $72 \%$ of respondents live in a household with at least two (2) persons

- $47 \%$ of participants are professionals

- $78 \%$ currently have at least (1) conventional vehicle and $92 \%$ agree that their vehicle (s) work with gasoline

- $57 \%$ have an average monthly income between \$ 1'000 000 (US \$ 526) and \$ 3'499 999 (US \$1 843)

Table II shows the user mobility patterns in the city and it can be seen that $68 \%$ of participants use their vehicle for going to work and that they daily travel an average distance of 12 to $60 \mathrm{~km}$, at an average speed between 31 and $60 \mathrm{~km} / \mathrm{h}$, requiring a daily travel time between 1 and 3 hours.

\begin{tabular}{|l|c|c|}
\multicolumn{2}{|c}{ TABLE II. } & DRIVING PATTERNS \\
\hline \multicolumn{1}{|c|}{ Patterns } & Indicator & $\%$ \\
\hline Daily travel time & $\begin{array}{c}\text { Between 1 and 3 } \\
\text { hours }\end{array}$ & 66 \\
\hline $\begin{array}{l}\text { Daily distance } \\
(\mathrm{km})\end{array}$ & $12-60$ & 77 \\
\hline Daily speed (km/h) & $31-60$ & 65 \\
\hline $\begin{array}{l}\text { Main purpose of } \\
\text { driving }\end{array}$ & $\begin{array}{c}\text { Going to work } \\
8: 59 \text { am and } \\
\text { between 3:00 pm- } \\
7: 59 \text { pm }\end{array}$ & 60 \\
\hline Driving schedule & $\begin{array}{c}\text { Between 6:00 am- } \\
\text {. }\end{array}$ & 68 \\
\hline
\end{tabular}

On the other hand, $72 \%$ of the respondents agreed that they usually park their vehicle at work or in a public parking lot (paying a fee).

\section{B. Requirements and constraints to acquire an EV}

It is necessary to identify why a person would be willing or not to change their conventional vehicle to an electrical technology one. In this study, the participants were asked about the needs that EVs must address and which the main reasons for not buying one are.

Fig. 1 indicates that, on average, $82 \%$ of the respondents conclude that when purchasing an $\mathrm{EV}$, the purchase price of the vehicle and its associated environmental impact is very important (rating five: 5).

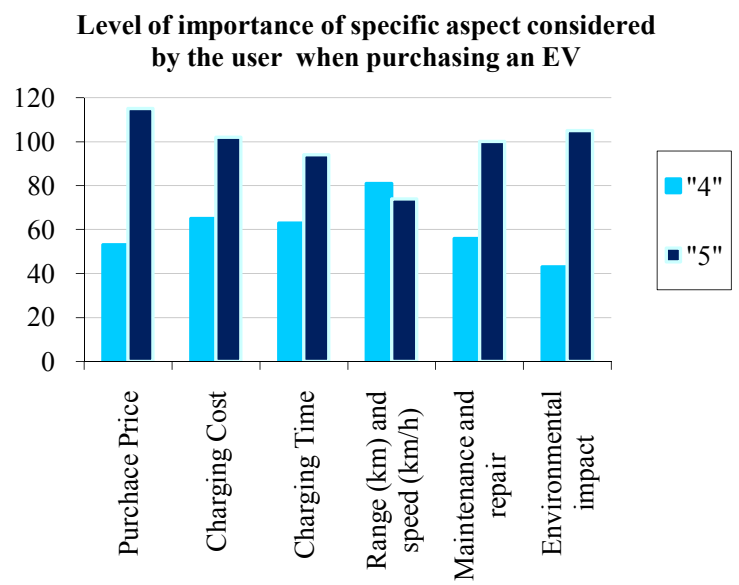

Figure 1. Level of importance of specific aspects when purchasing an EV

$67 \%$ of the participants concluded that the least important aspect to consider when purchasing an EV is its popularity.

Regarding the intention to buy an EV, 75\% of participants agreed that a familiar vehicle for five passengers (sedan or hatchback style) suits their needs better. Fig. 2 shows that $58 \%$ of participants concluded that in case of purchasing an EV in the next five years, they would like to recharge it at home. On average, $78 \%$ would be willing to charge their EVs only if this requires a time between 30 minutes and 6 hours as shown in Fig. 3.

After asking participants what the minimum range that an EV should have to seriously think about purchasing one is, $67 \%$ of 
them gave a value between 80 and $300 \mathrm{~km}$. This indicator shows that, in general, EVs have the potential to adapt to the daily needs of mobility in the city of Bogotá, especially considering that most commercial EVs have an average range over $150 \mathrm{~km}$.

\section{Place of preference for charging an EV in case} of purshasing one

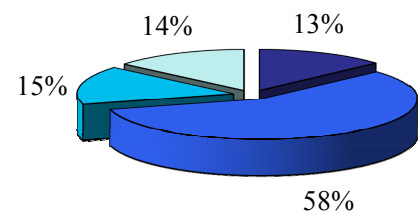

\begin{tabular}{|ll}
\hline 口On a public parking lot & $\square$ At Home \\
$\square$ At Work & $\square$ On the Street
\end{tabular}

Figure 2. Place of preference for charging an EV in case of purchasing one in the next five years

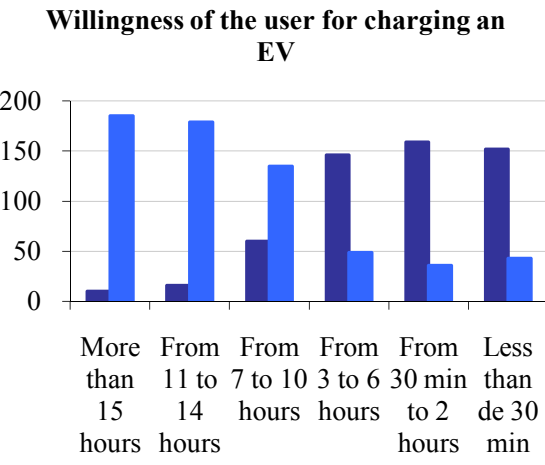

$\square$ Willing $\quad$ Uwilling

Figure 3. Willingness of the user for charging an EV for a period of time

Moreover, in terms of the main constraints that customers find when purchasing an EV, on average $70 \%$ of participants answered that the main five (5) issues are: price, lack of knowledge about EVs technologies, charging times, batteries lifetime and the power grid capacity to support the charging of EVs (distribution grid infrastructure), as shown in Table III.

TABLE III. MAIN CONSTRAINTS IN PURCHASING AN EV

\begin{tabular}{|c|c|c|c|}
\hline Aspect/ Level of importance & $\mathbf{4}$ & $\mathbf{5}$ & Total \\
\hline Purchase Price & $27 \%$ & $54 \%$ & $81 \%$ \\
\hline Lack of knowledge of EVs technologies & $19 \%$ & $54 \%$ & $73 \%$ \\
\hline Charging Modes/Levels & $37 \%$ & $36 \%$ & $73 \%$ \\
\hline Batteries lifetime & $31 \%$ & $42 \%$ & $73 \%$ \\
\hline Dimited range (km)and speed (km/h) & $33 \%$ & $34 \%$ & $68 \%$ \\
\hline Energy consumption & $33 \%$ & $32 \%$ & $65 \%$ \\
\hline Security & $23 \%$ & $41 \%$ & $64 \%$ \\
\hline
\end{tabular}

\section{COLOMBIAN ELECTRICITY MARKET AND EVS}

The wholesale electricity market in Colombia is a competitive market created by the Electricity Reform (Law 142 and 143 of 1994) in which generators, transmitters, distributors, retailers and large consumers of electricity or unregulated users participate. The CREG (Regulatory commission of energy and gas), establishes the rules for this market [8].

The market is divided into two segments: the bilateral trades market (long term) and the spot energy market (short term trades). Energy can be traded on spot energy market or through bilateral trades with other generators, retailers or directly to large consumers or unregulated users (those whose demand is $0.1 \mathrm{MW}$ or $55 \mathrm{MWh} /$ month).

Retailers sell energy to users and provide them the billing service. They sell energy to unregulated users thorough free prices and to regulated users through regulated prices. Retailers and unregulated users define energy trades with generators, setting the price of electricity without state intervention.

Regulated users have interaction with the electricity market through the behavior of the market prices and the prices at which their retailers make the transactions.

\section{A. Regulated electricity price}

The CREG through the regulation CREG-119/07 established the formula for electricity tariff for regulated users. This price is defined according to (2):

$C U_{n, m, i}=G_{m, i}+T_{m}+D_{n, m}+C V_{m, i}+P R_{n, m, i, j}+R_{m, i}$

Where:

$C U_{n, m, i}$ : Unit cost (\$/ kWh (kilowatt-hour)) users connected to voltage level $n$, in month $m$

$G_{m, i}$ : Energy purchase cost $(\$ / \mathrm{kWh})$ in month $m$, from retailer $i$

$T_{m}$ : Cost for using the national electricity transmission system $(\$ / \mathrm{kWh})$

$D_{n, m}$ : Cost for using the distribution electricity system $(\$ / \mathrm{kWh})$ for voltage level $n$, in month $m$

$C V_{m, i}$ : Cost for retailing process (billing centers, customers care, etc) $(\$ / \mathrm{kWh})$

$P R_{n, m, i, j}$ : Cost related to the transportation and reduction of energy losses $(\$ / \mathrm{kWh})$

$R_{m, i}:$ Cost related to restrictions and services associated to the generation sector assigned to the retailer $i(\$ / \mathrm{kWh})$

Thereby, the monthly electricity tariff is calculated. However, in the case of the residential sector, depending on the socioeconomic strata that a customer belongs to, there will be a subsidy or a recharge on the monthly electricity tariff. This has been issued by the National Congress in the Law 1117 of 2006. It defines a subsidy of $60 \%$ for stratum 1, 50\% for stratum 2 and $15 \%$ for stratum 3 . Stratum 4 pays the full rate of the electricity tariff. Stratum 5 and 6, pay a contribution of $20 \%$ charged on their electricity tariff. This methodology is shown on Fig. 4. 


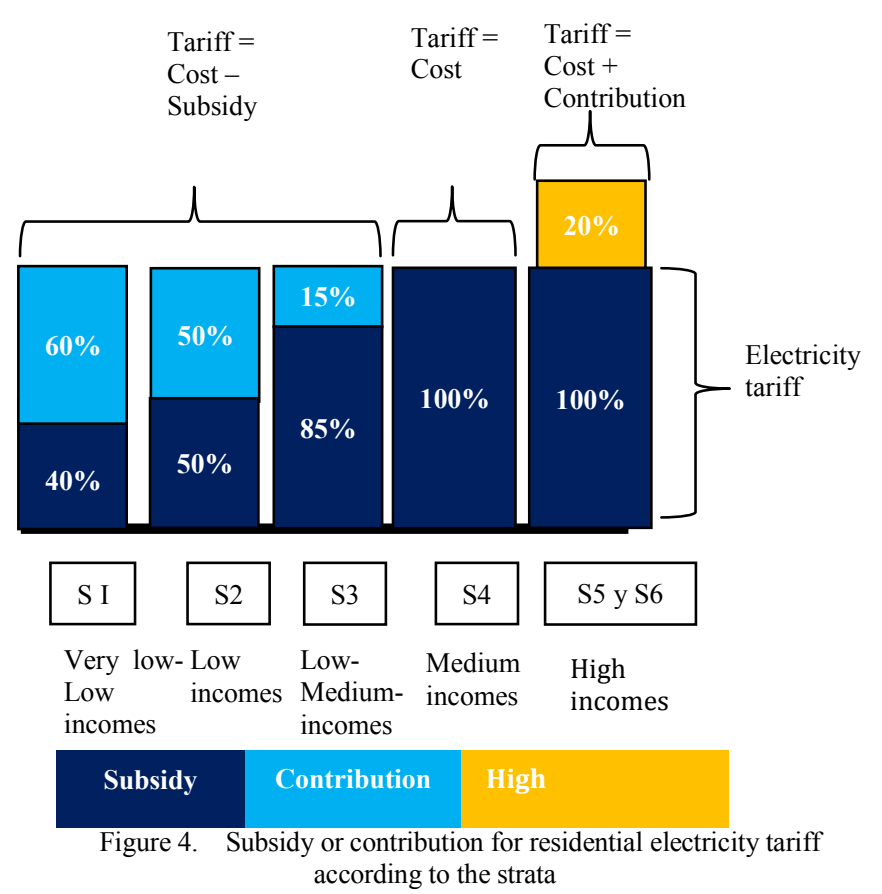

\section{B. Demand curve of the Bogotá residential sector}

The demand curve of the residential sector of Bogotá D.C. is shown in Fig. 5 [9]. As can be seen, the curve has three (3) peaks at the following times: $6: 00$ to $7: 00,12: 00$ to $13: 00$ and 20:00 to 21:00. These hours are associated with times when people make greater use of energy. Specifically, from 6:007:00 people prepares for going to work and students to institutions, from 12:00-14:00 is lunch time and some people return to home and from 20:00 - 21:00 after the working journey people come back home to cook and share time in family.

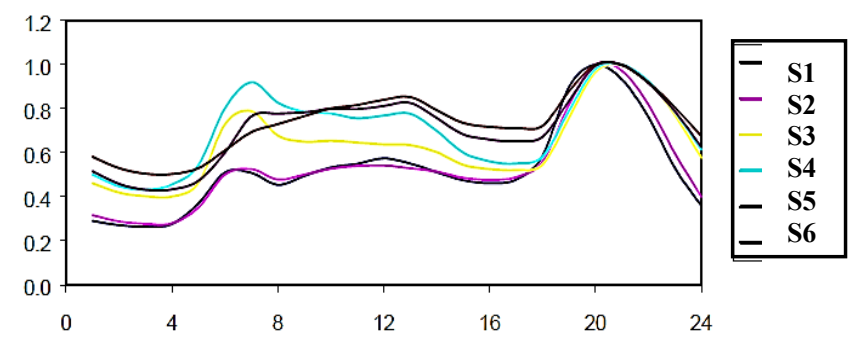

Figure 5. Demand curve in p.u. of the residential sector of Bogotá D.C.[9]

\section{EVs impact on the electricity market}

If there is a massive introduction of EVs, it is likely that most citizens will want to recharge their vehicle at home or at work. If this happens, many EVs would be connected to the grid at the same time and the load peaks would increase to a big scale. According to [10], if there is no control of the EVs charging process, the maximum power in the load curve may not be controlled.

This situation could produce a negative impact on the distribution grid, especially in older grids which would need infrastructure investments to be stable during peak hours.
Several studies have shown that if the battery recharging process is controlled as is modeled in [11], then the EVs recharging process can be distributed according to the peak or off-peak hours. Thus, the maximum power of the load curve of the city would decrease and the control of EVs recharging process could flatten the load curve, having several peaks (demand-side management) [12] [13]. This method has the main intention of motivating the user to consume less energy during peak hours in order to transfer the hours of energy consumption to off-peak hours: at night, when the price per $\mathrm{kWh}$ is lower, so the electric bill can be reduced, in countries with differentiated energy tariff.

In the case of Colombia, there is no regulation related to the energy tariff for recharging EVs. Currently, the rate for electricity consumption is set by the Regulatory Commission of Energy and Gas (CREG) as in (2) and is different for regulated and non-regulated users. In this market, for residential users the $\mathrm{kWh}$ price is charged monthly, keeping the same value throughout the month.

This means that it would be necessary to establish new schemes for the energy tariff in the Colombian electricity market. In other countries, the recharging process is included in the monthly energy bill and the user has the option of having a differentiated tariff depending on the recharging time. The "pay-as-you-consume" pricing scheme is applied through credit cards, when the recharging process is done in malls, on the street or in public parking lots. Also, EVs incentives are defined, such as allowing free EVs charging in some specific areas mandated by the government.

The impact of EVs on the electricity market mainly depends on the flexibility of users to recharge their EVs at different times from peak hours and on the electricity tariff assigned to the kWh consumed by the EVs.

According to the results of the survey and the information shown on figure 4 and 5 , it is concluded that incentives are needed to promote the use of EVs, under a scheme of a differentiated tariff depend on the hour for recharging an EV.

This new scheme not only benefits the user, who can regulate his energy consumption and reduce costs, but also the electricity market, because EVs could flatten the demand curve and consequently promote the efficient use of electricity.

In this way, under the existing tariff scheme, it is not possible to identify whether a stratum 6 user of an EV, recharge the $\mathrm{EV}$ at a relative, friend or colleague home of stratum 1, in order to pay less for energy consumption. This indicates that is required to set a different electricity tariff for the energy consumed by EVs or to design a system for identification of different loads, which recognizes when the load is an EV and associates a specific tariff to its consumption.

For this reason, mass adoption of EVs and their impact on the grid, depends by now on the user flexibility (how much are people willing to change their habits and adapt them to this new technology, identifying its limitations) and depends on the $\mathrm{kWh}$ tariff assigned to EVs, which is one of the main barriers for users to buy an EV. 
Similarly, it is important to identify driving patterns [3] and recharge modes required by users, because the impact on the grid depends on where, when and how many EVs are in recharging process simultaneously. Identifying all these points, will allow determining where the power grid is overloaded and where it needs to strengthen its infrastructure.

The electricity market can influence people, if it promotes the use of EVs, through economic incentives, that reflect benefits for those who use an EV. Also, it requires a regulatory framework that defines a tariff scheme under any EVs must operate in the country.

\section{CONCLUSIONS}

For Colombian cities, the change in the people's driving culture is a critical factor to face the challenge of reducing energy consumption and greenhouse emissions. Also, it is important to ensure the adoption of new vehicle technologies which foster sustainability and efficiency, like EVs.

The introduction of EVs raises questions regarding the impacts of these alternative technologies on the driving patterns of the customers, the mobility of cities, energy consumption, environmental impacts, charging times of EVs, comfort conditions and adaptation to new ranges and speeds. These aspects concern the customers because they will drive an EV in a different way than a conventional vehicle. For example, with a conventional vehicle, the user needs to refuel it once a week but with an EV the user will charge it every day with the electricity grid in order to fulfill the travel routines.

An aspect to consider are driving patterns [2] and charging modes required by customers, because the impact on the grid depends on where, when and how many EVs are being charged simultaneously. So, it is required to consider how to influence or change the driving culture and energy consumption patterns of the cities.

According to the results, customer would be willing to charge their EVs only if this requires a time between 30 minutes and 6 hours and also if it can be done at home. So, this might happen on peak hours, which finally impact negatively on the electricity grid.

This means that it would be necessary to establish new tariff scheme in the Colombian electricity market. The traditional method (in which power plants are called to increase their generation to meet the increasing demand in peak hours) needs to migrate to a demand side management scheme, in order to guarantee stabilization of the grid in real time: balance between electricity supply and demand. If the electricity market offers a series of incentives that benefit the user, they will adopt their habits to recharge their EVs when the electricity tariff has the lowest cost. In this way, not only the impact of EVs on the grid is reduced but the customer economy is preserved.

\section{REFERENCES}

[1] J. Riaño, H. Amaranto, J. Manrique. "Balances Energéticos 19752009”. UPME. Ministerio de Minas y Energía, Colombia,2010.

[2] L. Bertling, S. Lundmark, D. Steen, "Integration of plug in hybrid electric vehicles and electric vehicles - experience from Sweden", Power and Energy Society General Meeting, IEEE 2010: pp. 1-3.

[3] C. o. S. E. California, "California Plug-in Electric Vehicle Owner Survey," California Environmental Protection Agency, United States, 2012.

[4] P. I. L. (PwC), "Charging forward: Electric vehicle survey," Price wáter house Coopers International Limited (PwC), United States, 2011.

[5] D. C. LLP, "Gaining traction: A customer view of electric vehicle mass adoption in the U.S. automotive market," Deloitte Consulting LLP, United States, 2010.

[6] D. C. LLP, "Unplugged: Electric vehicle realities versus consumer expectation," Deloitte Consulting LLP, United States, 2011.

[7] DANE, Departamento Administrativo Nacional de Estadística, "Metodología Diseño Muestral Encuesta de Desempeño Institucional (EDI)”, 2006

[8] XM, expertos en Mercado. "Descripción Mercado Eléctrico Colombiano”, Medellín, 2012. Online: http://www.xm.com.co/Pages/DescripciondelSistemaElectricoColombi ano.aspx

[9] S. Ramírez, "Redes de distribución de energía”, $3^{\mathrm{a}}$ Edición, Universidad Nacional de Colombia, Manizales, 2004.

[10] P. Mitra, G. K. Venayagamoorthy, and K. Corzine, "Real-time study of a current controlled plug-in vehicle for vehicle-to-grid transaction", International Power Electronics Conference (IPEC), 2010.

[11] I. Hiskens and D. Callaway, "Achieving controllability of plug-in electric vehicles" in IEEE Vehicle Power and Propulsion Conference, 2009.

[12] K. Mets, T. Verschueren, W. Haerick, C. Develder, and F. D. Turck, "Optimizing smart energy control strategies for plug-in hybrid electric vehicle charging", IEEE/IFIP Network Operations and Management Symposium Workshops (NOMS Wksps), 2010.

[13] P. Grahn, L. Söder, "The Customer Perspective of the Electric Vehicles Role on the Electricity Market", 8th International Conference on the European Energy Market (EEM), 2011. 